\title{
CRESCIMENTO E PRODUÇÃO DE BANANEIRA PRATA- -ANÃ ADUBADA COM COMPOSTO ORGÂNICO DURANTE CINCO SAFRAS ${ }^{1}$
}

\author{
ERVAL RAFAEL DAMATTO JUNIOR ${ }^{2}$, ROBERTO LYRA VILLAS BÔAS 3 , SARITA LEONEL ${ }^{4}$, ED- \\ SON SHIGUEAKI NOMURA ${ }^{2}$, EDUARDO JUN FUZITANI ${ }^{2}$
}

\begin{abstract}
RESUMO - O presente trabalho objetivou avaliar a influência da adubação orgânica durante cinco safras, nas características de crescimento e produtividade de plantas de bananeira-'Prata-anã'. O experimento foi instalado no município de Botucatu-SP, em novembro de 2002, com mudas convencionais, adotando-se o espaçamento de $2,5 \times 2,5 \mathrm{~m}$, sendo as plantas adubadas com composto orgânico produzido a partir de serragem de madeira e esterco bovino devidamente compostados, que constituíram os tratamentos: 0; 43; 86; 129 e $172 \mathrm{~kg}$ de composto por planta, sendo estas doses de composto calculadas de acordo com o teor de potássio presente no composto. No florescimento das plantas em cada ciclo (2003, 2004, 2005, 2006 e 2007), foram medidas a circunferência do pseudocaule, a altura de inserção da inflorescência e determinou-se o número de folhas úteis por planta. Na colheita, foram determinados a massa do cacho, o número de frutos por cacho, o número de pencas por cacho, a massa da $2^{\mathrm{a}}$ penca, o número de frutos na $2^{\mathrm{a}}$ penca, o comprimento e o diâmetro de frutos da $2^{\mathrm{a}}$ penca. As doses de composto orgânico não causaram alterações nas características de crescimento das plantas; contudo, em função dos ciclos avaliados, foi possível observar queda no número de folhas a partir do segundo ciclo e alterações na altura de plantas e circunferência do pseudocaule. No presente trabalho, onde as doses de $\mathrm{K}_{2} \mathrm{O}$ oscilaram entre zero e $394 \mathrm{~g}$ por planta, os cachos com massa mais elevada foram obtidos com as duas maiores quantidades de compostos aplicadas, o que, economicamente, indica como a melhor dose a ser recomendada a de $129 \mathrm{~kg}$ de composto por planta, que fornece $290,5 \mathrm{~g}$ de $\mathrm{K}_{2} \mathrm{O}$ por planta.
\end{abstract}

Termos para indexação: Musa spp., potássio, adubação orgânica, nutrição.

\section{GROWTH AND PRODUCTION OF BANANA PRATA-ANÃ FERTILIZED WITH ORGANIC COMPOST DURING FIVE CROPS}

\begin{abstract}
This study aimed to evaluate the influence of organic manure for five crops, on growth and yield characteristics of banana 'Prata-anã'. The experiment was installed in Botucatu, SP, Brazil, in November 2002 with conventional plants spaced 2.5 x $2.5 \mathrm{~m}$. Plants were fertilized with organic compost produced with sawdust and manure, properly composted, which provided the following treatments: 0,43 , 86,129 and $172 \mathrm{~kg}$ of compost per plant. The compost rates were calculated according to the potassium content in the compost. In 2003, 2004, 2005, 2006 and 2007, at blooming, the pseudostem circumference and the plants height were evaluated, as well as the number of living leaves per plant. At harvest, the bunch weight, the number of fruits per bunch, the number of hands per bunch, the bunch weight of the $2^{\text {nd }}$, the number of fruits in the $2^{\text {nd }}$ bunch, the fruit length and diameter were evaluated. The organic compost rates did not influence the plant growth. However, concerning the crop cycles it was observed a decrease in the leaves number from the second cycle on, and also changes in plants height and pseudostem circumference. In this study, where the $\mathrm{K}_{2} \mathrm{O}$ rates ranged from zero to $394 \mathrm{~g}$ per plant, the bunches of higher weight were obtained with the two higher amounts of compost, which indicates that economically, the dose of $129 \mathrm{~kg}$ compost per plant, which corresponds to $290.5 \mathrm{~g}$ of $\mathrm{K}_{2} \mathrm{O}$ per plant, is the best to be recommended.
\end{abstract}

Index terms: Musa spp., potassium, organic fertilization, nutrition.

\footnotetext{
${ }^{1}$ Trabalho Sinfruit 117 - Simpósio Internacional de Fruticultura - Avanços na Fruticultura (17 a 21 Outubro)

${ }^{2}$ Pesquisadores científicos da APTA, Pólo Regional do Vale do Ribeira. - Rod. Régis Bittencourt, km 460, Cx. P:122, Cep: 11900-000, Registro-SP.E-mail: erval@apta.sp.gov.br; edsonnomura@apta.sp.gov.br, edufuzitani@apta.sp.gov.br.

${ }^{3}$ Prof. Dr. do Depto. de Recursos Naturais - Solos da Faculdade de Ciências Agronômicas/UNESP, Cep: 18610-307 - Botucatu-SP. E-mail: rlvboas@fca.unesp.br.

${ }^{4}$ Prof $^{\mathrm{a}}$. Dr ${ }^{\mathrm{a}}$. do Depto. de Produção Vegetal - Horticultura da Faculdade de Ciências Agronômicas/UNESP, Cep: 18610-307 - Botucatu-SP. E-mail: sarinel@fca.unesp.br.
} 


\section{INTRODUÇÃO}

A banana é uma das frutas mais consumidas no mundo, explorada na maioria dos países tropicais, sendo atingida uma produção mundial de 97,4 milhões de toneladas em 2009 (FAO, 2011). O Brasil tem mais de 500 mil hectares plantados com banana e uma produção anual em torno de sete milhões de toneladas, sendo que quase a totalidade da produção se destina ao mercado interno. A cultura da banana ocupa o segundo lugar em volume de frutas produzidas e consumidas no Brasil e o terceiro em área colhida. A produção brasileira de banana está distribuída por todo o território nacional, sendo a região Nordeste a maior produtora (34\%), seguida das regiões Norte (26\%), Sudeste (24\%), Sul (10\%) e Centro-Oeste (6\%), num total de cerca de 520.000 ha (CORDEIRO, 2007).

A produção de bananas no sistema orgânico aparece como alternativa para que o produto final possa atingir uma parcela de consumidores específica, com maior poder aquisitivo (AGRIANUAL, 2001), bem como é uma alternativa de redução de custos, uma vez que os adubos químicos têm sofrido elevados aumentos nos últimos anos, além de ser um método mais sustentável de cultivo, gerando menores impactos ao ambiente.

As bananeiras respondem de forma favorável à adubação orgânica, pois além de fornecer nutrientes, ela ajuda a melhorar as características físicas do solo, mantendo a umidade, bem como auxilia no aumento da diversidade biológica (MOREIRA, 1987). Kiehl (1985) relatou que os adubos orgânicos, mesmo sendo considerados de baixa concentração em nutrientes, por serem empregados na lavoura em doses elevadas, podem tornar-se excelentes fornecedores de todos os nutrientes necessários às plantas, como nitrogênio, fósforo, potássio, cálcio, magnésio, enxofre e micronutrientes.

Desta forma, o presente trabalho objetivou avaliar a influência da adubação orgânica durante cinco safras, nas características de crescimento e produtividade de plantas de bananeira-'Prata-anã' cultivadas no município de Botucatu-SP.

\section{MATERIAL E MÉTODOS}

O presente trabalho foi conduzido no município de Botucatu-SP $\left(22^{\circ} 52^{\prime} \mathrm{S}, 48^{\circ} 26^{\prime} \mathrm{W}\right.$ e altitude $786 \mathrm{~m}$ ), num solo classificado como Nitossolo Vermelho e instalado em novembro de 2002 com mudas convencionais de bananeira cv. Prata-anã (Musa $\mathrm{AAB}$ ), adotando-se o espaçamento de 2,5 m entre linhas e 2,5 m entre plantas, sendo as plantas adu- badas com composto orgânico produzido a partir de serragem de madeira e esterco bovino devidamente compostados, que ao final do processo apresentou as seguintes características: $\mathrm{pH}=7,5$; relação $\mathrm{C} / \mathrm{N}=$ $25 / 1$; umidade $=62 \% ; \mathrm{MO}=77 \%$; $\mathrm{em} \mathrm{g} \mathrm{kg}^{-1}(\mathrm{x} 10)$ : $\mathrm{N}=1,75 ; \mathrm{P}_{2} \mathrm{O}_{5}=1,44 ; \mathrm{K}_{2} \mathrm{O}=0,60 ; \mathrm{Ca}=1,96 ; \mathrm{Mg}=$ 0,$33 ; \mathrm{S}=0,30 ; \mathrm{C}=42,78 ;$ e em mg kg-1: $\mathrm{Fe}=2450$; $\mathrm{Cu}=56 ; \mathrm{Mn}=114 ; \mathrm{Na}=1.600 ; \mathrm{Zn}=112$.

$\mathrm{Na}$ área experimental adotou-se o sistema de irrigação localizada (microaspersão), com vazão de emissores de $40 \mathrm{~L} \mathrm{~h}^{-1}$. As características químicas iniciais do solo, na camada de 0 a $20 \mathrm{~cm}$, foram as seguintes: $\mathrm{pH}\left(\mathrm{CaCl}_{2}\right)=5,9 ; \mathrm{MO}=28 \mathrm{~g} \mathrm{dm}^{-3} ; \mathrm{P}$

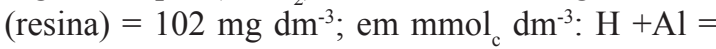
$31 ; \mathrm{K}=4,2 ; \mathrm{Ca}=65 ; \mathrm{Mg}=22 ; \mathrm{SB}=91 ; \mathrm{CTC}=122$ e $\mathrm{V}=75 \%$; e em mg dm${ }^{-3}: \mathrm{B}=0,19 ; \mathrm{Cu}=3,8 ; \mathrm{Fe}=$ $23 ; \mathrm{Mn}=11,6$ e $\mathrm{Zn}=2,3$.

Os tratamentos empregados foram constituídos por cinco doses de composto orgânico $(0 ; 43$; $86 ; 129$ e $172 \mathrm{~kg}$ por planta) calculadas de acordo com o teor de potássio presente no composto. A adubação anual, utilizando o composto como fonte de nutrientes no primeiro ciclo (2003), foi dividida em cinco parcelas, aplicadas a cada dois meses, nas quantidades determinadas para cada tratamento ao redor das plantas da família, num raio de 1,25 m. Os tratamentos não foram aplicados para a produção das plantas do $2^{\circ}$ e $3^{\circ}$ ciclos (2004 e 2005), objetivando diminuir os teores de potássio no solo e nas plantas da família. Para a produção do $4^{\circ}$ e $5^{\circ}$ ciclos (2006 e 2007), a adubação foi retomada, sendo o parcelamento da adubação do $4^{\circ}$ ciclo feito em três etapas, e no $5^{\circ}$ ciclo, parcelada em quatro vezes.

Empregou-se delineamento experimental em blocos casualizados, com cinco tratamentos, cinco repetições e duas plantas úteis por parcela, sendo os efeitos dos tratamentos aplicados às parcelas avaliados empregando-se o teste de $\mathrm{F} \mathrm{e}$, para as situações nas quais foram detectados efeitos significativos dos tratamentos de adubação, foram ajustadas equações de regressão.

No florescimento das plantas em cada ciclo (2003, 2004, 2005, 2006 e 2007), foram medidas a circunferência do pseudocaule a $30 \mathrm{~cm}$ acima do nível do solo, a altura da planta do solo até a inserção da inflorescência e determinou-se o número de folhas úteis por planta.

As colheitas foram realizadas nos anos de 2003, 2004, 2005, 2006 e 2007, momento no qual foram determinados a massa do cacho $(\mathrm{kg})$; o número de frutos por cacho; o número de pencas por cacho; a massa da $2^{\mathrm{a}}$ penca $(\mathrm{kg})$; o número de frutos na $2^{\mathrm{a}}$ penca; o comprimento e o diâmetro de frutos da $2^{\mathrm{a}}$ penca. 


\section{RESULTADOS E DISCUSSÃO}

Com os dados obtidos nos 5 ciclos produtivos da bananeira-'Prata-anã' avaliados e apresentados na Tabela 1, observa-se que em nenhum deles foi detectada influência das doses de composto orgânico nas características de crescimento estudadas.

A altura média das plantas aumentou progressivamente até o $3^{\circ}$ ciclo, apresentando como médias $2,65 \mathrm{~m} ; 3,46 \mathrm{~m}$ e $3,55 \mathrm{~m}$, no $1^{\circ}, 2^{\circ}$ e $3^{\circ}$ ciclos, respectivamente; já no $4^{\circ}$ ciclo; a altura $(3,35 \mathrm{~m})$ foi inferior ao $2^{\circ}$ e $3^{\circ}$ ciclos, porém superior ao $1^{\circ}$ ciclo e $5^{\circ}$ ciclo (3,10 m). De acordo com Santos et al. (2006), é indesejável que a bananeira seja muito alta, pois pode dificultar a colheita e provocar o tombamento da planta em decorrência de ventos fortes e ataques de nematoides e broca. Além disso, a altura da planta é um descritor importante, tanto do ponto de vista fitotécnico como genético, permitindo maior adensamento e, consequentemente, maiores produtividades.

A circunferência do pseudocaule teve aumento significativo do $1^{\circ}$ para o $2^{\circ}$ ciclo, enquanto no $3^{\circ}$ ciclo decresceu, sendo os dados médios de 75,84 $\mathrm{cm} ; 95,42 \mathrm{~cm}$ e $88,50 \mathrm{~cm}$, respectivamente; já no $4^{\circ}$ ciclo, as plantas apresentaram circunferência média de $85,36 \mathrm{~cm}$ e $78,96 \mathrm{~cm}$ no $5^{\circ}$ ciclo. Silva e Alves (1999) relatam que a circunferência do pseudocaule está relacionada ao vigor e reflete a capacidade de sustentação do cacho, por isso quanto maior diâmetro, menor a suscetibilidade ao tombamento.

Pela Tabela 1 , verifica-se que não houve diferença significativa $(p>0,05)$ entre os tratamentos para o número de folhas em todos os ciclos estudados, apresentando em média 17,42 folhas por planta no primeiro, 10,06 folhas no segundo, 9,18 folhas no terceiro, 9,24 folhas no quarto e 9,00 folhas no quinto ciclo. O número de folhas no momento do florescimento, no $2^{\circ}, 3^{\circ}, 4^{\circ}$ e $5^{\circ}$ ciclos, foi estatisticamente igual e inferior aos observados no $1^{\circ}$ ciclo. Ramos et al. (2009) observaram que, para a cv. Prata-anã, o número folhas no florescimento foi de 12,8 , valor esse inferior aos observados no primeiro ciclo deste trabalho e superior aos demais. Essa queda no número de folhas mostra que plantas nutridas inadequadamente perdem mais rapidamente suas folhas, o que acarreta em perdas em produção, uma vez que a incidência da Sigatoka-amarela foi muito baixa e controlada, conforme recomendações para a cultura; além disso, não foram observadas outras doenças foliares que pudessem comprometer a área foliar e, consequentemente, o número de folhas. Segundo Soto Ballestero (1992), a presença de mais de oito folhas no florescimento é um fator considerado como suficiente para o desenvolvimento normal do cacho; assim sendo, os valores obtidos para número de folhas neste trabalho são considerados satisfatórios.

O período entre o florescimento e a colheita também não foi influenciado pelos tratamentos aplicados, apresentando como médias: 167; 188,; 163; 181 e 158 dias no $1^{\circ}, 2^{\circ}, 3^{\circ}, 4^{\circ}$ e $5^{\circ}$ ciclos, respectivamente. Contudo, observaram-se variações significativas no número de dias do florescimento até a colheita entre os ciclos, como pode ser observado na Tabela 1; porém, essas variações são inferiores a um mês, sendo que a maior diferença foi de 23 dias, quando se compara o $4^{\circ}$ com o $5^{\circ}$ ciclo. Salienta-se que essas diferenças de dias entre florescimento e colheita possam ser causadas pelas condições climáticas, que variam muito entre os anos e que, certamente, influenciaram nesses resultados obtidos, pois Ramos el al. (2009), nas mesmas condições climáticas às deste trabalho, observaram para a bananeira-'Prata-anã' que esse período foi de 126 dias.

A maior parte dos parâmetros avaliados relacionados à produção do primeiro ao quinto ciclo da bananeira-'Prata-anã', como número de frutos por cacho, número de pencas por cacho e massa da $2^{\mathrm{a}}$ penca, não demonstrou diferença significativa para os tratamentos aplicados, estando seus resultados apresentados na Tabela 2. Diversos autores comentam que a bananeira demora em responder à adubação aplicada, em especial à adubação potássica. Silva et al. (2003) só observaram efeitos significativos para a aplicação de doses de potássio em bananeira-'Prata- anã' no $4^{\circ}$ ciclo de produção, uma vez que o solo onde foi instalado o experimento apresentava teor de $\mathrm{K}$ acima de 5,0 $\mathrm{mmol}_{\mathrm{c}} \mathrm{dm}^{-3}$, valor este considerado alto. A máxima produção estimada para $\mathrm{o}$ $4^{\circ}$ ciclo foi alcançada com a aplicação de $962,5 \mathrm{~kg}$ de $\mathrm{K}_{2} \mathrm{O} \cdot \mathrm{ha}^{-1}$.ano ${ }^{-1}$, o que promoveu incremento de $11,2 \%$ na produção. Fato semelhante ocorreu neste trabalho, em que, no primeiro ciclo, os teores de potássio no solo estavam elevados, e as plantas não responderam significativamente aos tratamentos, e somente no $5^{\circ}$ ciclo a massa do cacho foi influenciada pela adubação, sendo que as plantas adubadas com as duas maiores doses de composto apresentaram as maiores massas de cacho: 13,27 e 13,96 kg para as doses de 129 e $172 \mathrm{~kg}$ de composto por planta, o que corresponde à aplicação de 468,8 e 630,4 kg de $\mathrm{K}_{2} \mathrm{O}$ ha $^{-1} \cdot$ ano $^{-1}$, respectivamente e que proporcionou o aumento de produtividade em 32 e $35 \%$, respectivamente, quando comparados com a testemunha.

Guerra et al. (1986) conseguiram aumentos significativos na produção de banana com a aplicação de potássio a partir de $400 \mathrm{~kg}$ de $\mathrm{K}_{2} \mathrm{O} \cdot \mathrm{ha}^{-1}$. ano $^{-1}$, enquanto Brasil et al. (2001) obtiveram produção 
ótima da bananeira cv. Pioneira com aplicação de 370 e $270 \mathrm{~kg}$ de $\mathrm{K}_{2} \mathrm{O} \cdot \mathrm{ha}^{-1}$. ano $^{-1}$, obtendo aumentos de produção da ordem de 73 e $39 \%$, no $2^{\circ}$ e $3^{\circ}$ ciclos, respectivamente.

Avaliando-se a evolução da massa média do cacho, verifica-se, através da Tabela 2, que houve elevação significativa do $1^{\circ}$ para o $2^{\circ}$ ciclo em função da adubação aplicada no primeiro ano, que serviu como fonte de reserva de nutrientes para as plantas da família, passando de $16,36 \mathrm{~kg}$ para $17,05 \mathrm{~kg}$. Contudo, no $3^{\circ}$ ciclo, houve decréscimo significativo na massa dos cachos $(14,04 \mathrm{~kg})$, provavelmente devido ao esgotamento das reservas de nutrientes do solo e das reservas das plantas da família, uma vez que não foi realizada a aplicação de nenhuma fonte de nutriente durante o $2^{\circ}$ e o $3^{\circ}$ ciclos e, mesmo quando retomada a adubação no $4^{\circ}$ ciclo, observou-se que a massa média dos cachos manteve-se em queda significativa $(13,03 \mathrm{~kg})$, sendo possivelmente causada pelo longo período em que as plantas não foram adubadas (dois ciclos). Tanto no $4^{\circ}$ como no $5^{\circ}$ ciclos, foram observadas as menores massas de cacho. Mesmo com as quedas na massa de cachos, os valores médios obtidos neste trabalho são superiores aos encontrados por diversos autores. Gomes (2004), Rodrigues et al. (2001), Pereira et al. (2001) e Ramos et al. (2009), trabalhando com a cv. Prata-anã, encontraram massa média de cacho de $10,45 \mathrm{~kg} ; 12,49 \mathrm{~kg} ; 11,10 \mathrm{~kg}$ e 9,50, respectivamente.

Com os dados médios de massa de cacho e com a densidade de 1.600 plantas por hectare, determinou-se a produtividade média para todos os anos avaliados, que apresentaram produtividades de 26,$18 ; 27,28 ; 22,46 ; 20,85$ e 18,78 tha $^{-1}$, valores esses superiores à média do País, que foi de $19,8 \mathrm{t} \mathrm{ha}^{-1}$ no ano de 2008 (FAO, 2011), exceto no $5^{\circ}$ ciclo.

Com os resultados de produção do $5^{\circ}$ ciclo da bananeira-'Prata-anã' sob adubação orgânica, observa-se, por meio da Figura 1, que houve aumento linear da massa de cachos, bem como no número de frutos por cacho, número de pencas por cacho e o número de frutos na $2^{\mathrm{a}}$ penca; assim sendo, é possível inferir que o aumento das doses de composto favoreceu tais parâmetros produtivos; contudo, verifica-se, através da Tabela 2, que a massa de cacho para as duas maiores doses testadas é significativamente semelhante e, por motivos econômicos, recomenda-se a aplicação da dose de $129 \mathrm{~kg}$ de composto por planta.

No $4^{\circ}$ ciclo, verificou-se que o maior número de frutos na $2^{\mathrm{a}}$ penca foi encontrado na testemunha (15,8 frutos) e também com a aplicação da maior dose de composto (172 kg por planta), em que a segunda penca possuía em média 16,0 frutos. Contudo, os maiores frutos em comprimento foram encontrados com a aplicação de $129 \mathrm{~kg}$ de composto por planta, sendo o comprimento médio de $16,59 \mathrm{~cm}$.

Tanto para o número médio de frutos por cacho como para o número de pencas por cacho, houve um aumento significativo do $1^{\circ}$ para o $2^{\circ}$ ciclo. $\mathrm{O}$ número de pencas por cacho manteve-se estável até o $4^{\circ}$ ciclo (Tabela 2), e no último ano de avaliação (2007) verificou-se queda significativa para 9,08 pencas. Rodrigues et al. (2002) obtiveram 8,6 pencas por cacho, número esse inferior aos encontrados em todos os ciclos avaliados neste trabalho.

A massa média da $2^{\mathrm{a}}$ penca mostrou-se superior na $1^{\mathrm{a}}$ e $2^{\mathrm{a}}$ colheitas $(1,99$ e $1,74 \mathrm{~kg})$, uma vez que apresentou maior número de frutos, bem como maior comprimento e diâmetro de frutos em suas pencas. A partir da $3^{\text {a }}$ colheita, verificou-se queda significativa na massa da $2^{\mathrm{a}}$ penca, que se manteve estável até a $5^{\text {a }}$ colheita (Tabela 2). Rodrigues et al. (2002) determinaram a massa média da $2^{\mathrm{a}}$ penca de banana-'Prata-anã' de 1,68 kg, valor este inferior aos encontrados nas duas primeiras colheitas, porém superior às demais.

No $2^{\circ}$ ciclo, o diâmetro dos frutos foi o único parâmetro avaliado que apresentou diferença, sendo os frutos com maior diâmetro encontrados na testemunha $(34,58 \mathrm{~mm})$; contudo, os frutos nessa segunda colheita apresentaram-se, em média, menores que os do ciclo anterior, possivelmente devido à não aplicação da adubação. Nos ciclos subsequentes, o diâmetro dos frutos não mostrou diferenças significativas entre os tratamentos.

O tamanho dos frutos, avaliados através das mensurações do comprimento e do diâmetro, apresentou tendência de diminuição com a supressão de nutrientes ao solo, apresentando como médias no $1^{\circ}$ ciclo de $13,02 \mathrm{~cm}$ e $36,29 \mathrm{~mm}$, no $2^{\circ}$ ciclo $12,48 \mathrm{~cm} \mathrm{e}$ $32,59 \mathrm{~mm}$ e no $3^{\circ}$ ciclo $11,77 \mathrm{~cm}$ e $30,99 \mathrm{~mm}$, respectivamente, para comprimento e o diâmetro. A partir da retomada na adubação das plantas, verificou-se resposta significativa no tamanho dos frutos, sendo que o comprimento aumentou para $13,73 \mathrm{~cm}$ no $4^{\circ}$ e $5^{\circ}$ ciclos, e o diâmetro aumentou para $33,89 \mathrm{~mm}$ no $4^{\circ}$ ciclo e para $34,55 \mathrm{~mm}$ no $5^{\circ}$ ciclo (Tabela 2 ). Esses resultados indicam que as características de tamanho de fruto, avaliadas através do comprimento e diâmetro, são altamente responsivas à adubação aplicada.

Com relação ao comprimento dos frutos, eles são semelhantes aos encontrados por Rodrigues et al. (2001) e superiores os verificados por Guerra (2001), que obteve frutos com comprimento de 10 $\mathrm{cm}$. O diâmetro médio dos frutos da $2^{\mathrm{a}}$ penca, em quase todos os anos, foram superiores aos observados 
por Rodrigues et al. (2001), que obtiveram frutos com diâmetro médio de $32 \mathrm{~mm}$; porém a questão de diâmetro de frutos é bastante variável, pois este é um dos fatores que determinam o ponto ideal de colheita, dependendo do destino que se pretende dar aos frutos, pois normalmente frutos para consumo local são colhidos com diâmetros maiores, enquanto frutos para serem transportados a distâncias maiores são colhidos com diâmetros menores.
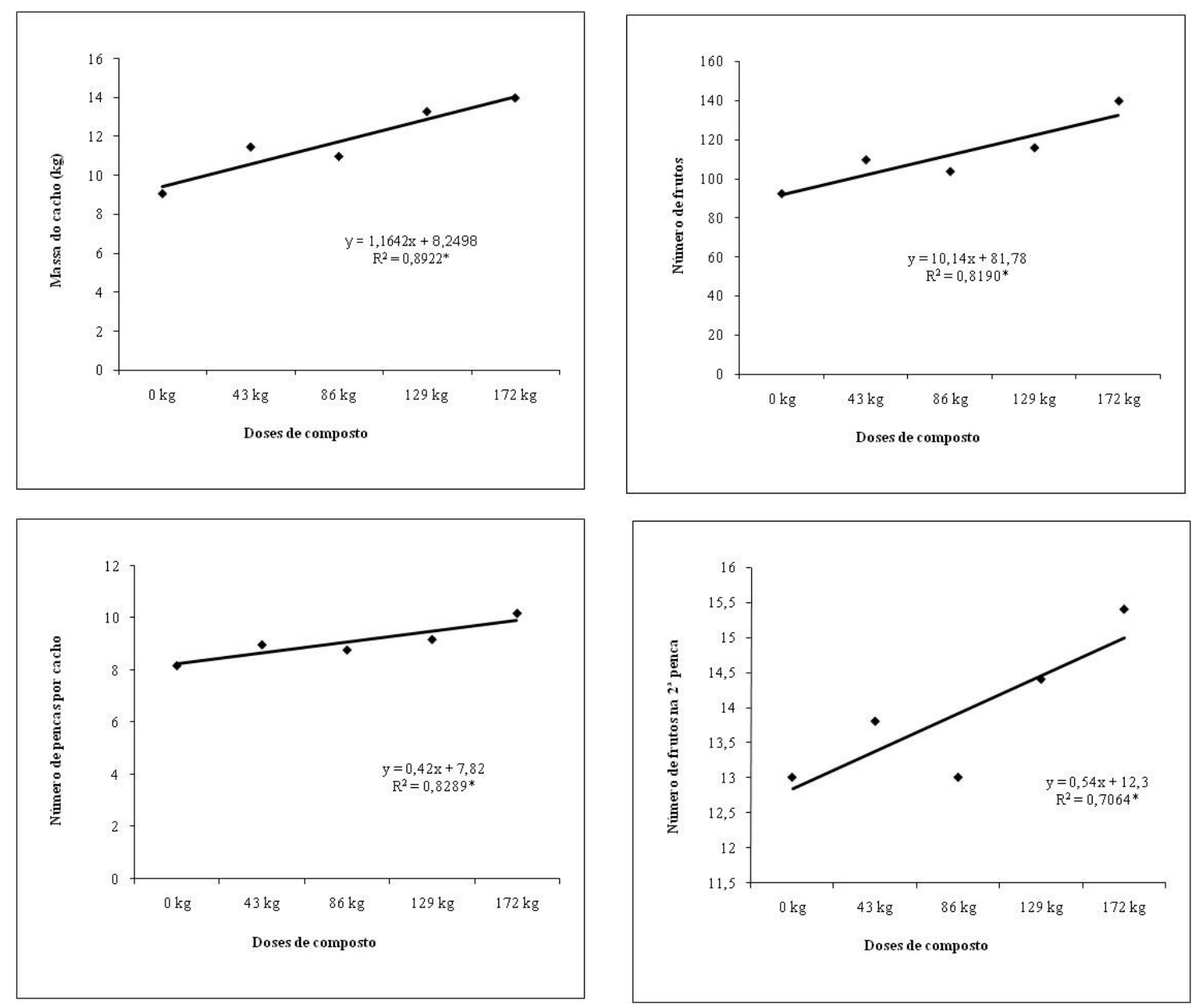

FIGURA 1 - Massa de cachos, número de frutos por cacho, número de pencas por cacho e número de frutos na $2^{\mathrm{a}}$ penca de bananeira-'Prata-anã' adubada com doses de composto orgânico no $5^{\circ}$ ciclo. 
TABELA 1 - Valores médios de altura de plantas, circunferência de pseudocaule, número de folhas por planta e número de dias entre o florescimento e a colheita de bananeira-'Prata-anã', adubada com diferentes doses de composto orgânico do $1^{\circ}$ ao $5^{\circ}$ ciclo de produção. Botucatu-SP (2002 a 2007).

\begin{tabular}{|c|c|c|c|c|c|}
\hline Ano & Tratamentos & $\begin{array}{c}\text { Altura de } \\
\text { Plantas (m) }\end{array}$ & $\begin{array}{l}\text { Circunferência } \\
\text { Pseudo.(cm) }\end{array}$ & $\begin{array}{l}\mathrm{N}^{\circ} \text { folhas } \\
\text { por planta }\end{array}$ & D.A.F. \\
\hline \multirow{7}{*}{2003} & T1: 0 kg composto/planta & 2,71 & 76,40 & 18,30 & 166,40 \\
\hline & T2: $43 \mathrm{~kg}$ composto/planta & 2,66 & 76,70 & 16,30 & 169,80 \\
\hline & T3: 86 kg composto/planta & 2,69 & 76,30 & 16,90 & 167,40 \\
\hline & $\mathrm{T} 4: 129 \mathrm{~kg}$ composto/planta & 2,60 & 75,70 & 17,40 & 167,40 \\
\hline & T5: $172 \mathrm{~kg}$ composto/planta & 2,61 & 74,10 & 18,20 & 163,80 \\
\hline & Médias & $2,65 \mathrm{D}$ & $75,84 \mathrm{C}$ & $17,42 \mathrm{~A}$ & $166,96 \mathrm{BC}$ \\
\hline & F para doses & $0,40^{\mathrm{ns}}$ & $0,20^{\mathrm{ns}}$ & $1,46^{\mathrm{ns}}$ & $0,07^{\mathrm{ns}}$ \\
\hline Ano & Tratamentos & & & & \\
\hline \multirow{7}{*}{2004} & T1: 0 kg composto/planta & 3,46 & 95,60 & 10,40 & 181,00 \\
\hline & T2: $43 \mathrm{~kg}$ composto/planta & 3,42 & 94,80 & 10,20 & 184,80 \\
\hline & T3: 86 kg composto/planta & 3,46 & 95,80 & 9,40 & 192,40 \\
\hline & T4: $129 \mathrm{~kg}$ composto/planta & 3,46 & 94,10 & 10,30 & 193,80 \\
\hline & T5: $172 \mathrm{~kg}$ composto/planta & 3,47 & 96,80 & 10,00 & 190,20 \\
\hline & Médias & $3,46 \mathrm{AB}$ & $95,42 \mathrm{~A}$ & $10,06 \mathrm{~B}$ & $188,44 \mathrm{~A}$ \\
\hline & F para doses & $0,07^{\mathrm{ns}}$ & $0,19^{\mathrm{ns}}$ & $0,32^{\mathrm{ns}}$ & $0,46^{\mathrm{ns}}$ \\
\hline Ano & Tratamentos & & & & \\
\hline \multirow{7}{*}{2005} & T1: 0 kg composto/planta & 3,67 & 93,40 & 8,00 & 165,20 \\
\hline & $\mathrm{T} 2: 43 \mathrm{~kg}$ composto/planta & 3,26 & 88,30 & 8,60 & 159,80 \\
\hline & T3: 86 kg composto/planta & 3,60 & 88,00 & 9,60 & 161,60 \\
\hline & T4: $129 \mathrm{~kg}$ composto/planta & 3,68 & 87,10 & 10,50 & 161,80 \\
\hline & T5: $172 \mathrm{~kg}$ composto/planta & 3,54 & 85,70 & 10,50 & 167,80 \\
\hline & Médias & $3,55 \mathrm{~A}$ & $88,50 \mathrm{~B}$ & $9,18 \mathrm{~B}$ & $163,24 \mathrm{C}$ \\
\hline & F para doses & $4,61 *$ & $1,58^{\mathrm{ns}}$ & $1,83^{\mathrm{ns}}$ & $0,16^{\mathrm{ns}}$ \\
\hline Ano & Tratamentos & & & & \\
\hline \multirow{7}{*}{2006} & T1: $0 \mathrm{~kg}$ composto/planta & 3,38 & 86,40 & 9,30 & 201,00 \\
\hline & T2: $43 \mathrm{~kg}$ composto/planta & 3,30 & 84,20 & 8,30 & 177,60 \\
\hline & T3: 86 kg composto/planta & 3,28 & 83,70 & 8,70 & 174,20 \\
\hline & T4: $129 \mathrm{~kg}$ composto/planta & 3,37 & 84,80 & 10,40 & 170,80 \\
\hline & T5: $172 \mathrm{~kg}$ composto/planta & 3,42 & 87,70 & 9,50 & 183,80 \\
\hline & Médias & $3,35 \mathrm{~B}$ & $85,36 \mathrm{~B}$ & $9,24 \mathrm{~B}$ & $181,48 \mathrm{AB}$ \\
\hline & F para doses & $0,56^{\mathrm{ns}}$ & $0,51^{\mathrm{ns}}$ & $1,30^{\mathrm{ns}}$ & $2,25^{\text {ns }}$ \\
\hline Ano & Tratamentos & & & & \\
\hline \multirow{8}{*}{2007} & T1: 0 kg composto/planta & 3,11 & 77,20 & 8,40 & 145,20 \\
\hline & T2: $43 \mathrm{~kg}$ composto/planta & 3,01 & 77,00 & 8,60 & 159,20 \\
\hline & T3: 86 kg composto/planta & 3,07 & 77,00 & 8,40 & 152,80 \\
\hline & T4: $129 \mathrm{~kg}$ composto/planta & 3,20 & 84,60 & 9,00 & 165,00 \\
\hline & T5: $172 \mathrm{~kg}$ composto/planta & 3,09 & 79,00 & 10,60 & 168,20 \\
\hline & Médias & $3,10 \mathrm{C}$ & $78,96 \mathrm{C}$ & $9,00 \mathrm{~B}$ & $158,08 \mathrm{C}$ \\
\hline & F para doses & $0,77^{\mathrm{ns}}$ & $1,98^{\mathrm{ns}}$ & $1,73^{\mathrm{ns}}$ & $1,37^{\text {ns }}$ \\
\hline & $\mathrm{CV}(\%)$ & 5,52 & 6,12 & 14,36 & 10,36 \\
\hline
\end{tabular}

Médias seguidas por letras maiúsculas distintas na coluna diferem, pelo teste de Tukey, a 5\% para os anos. 
TABELA 2 - Valores médios de massa de cacho, número de frutos por cacho, número de pencas por cacho, massa da $2^{\mathrm{a}}$ penca, número de frutos na $2^{\mathrm{a}}$ penca, comprimento e diâmetro de frutos de bananeira-'Prata-anã', adubada com diferentes doses de composto orgânico em 5 safras. Botucatu-SP (2002 a 2007).

\begin{tabular}{|c|c|c|c|c|c|c|c|c|}
\hline Ano & Tratamentos & $\begin{array}{l}\text { Massa } \\
\text { cacho } \\
(\mathrm{kg})\end{array}$ & $\begin{array}{l}\text { Frutos/ } \\
\text { cacho }\end{array}$ & $\begin{array}{l}\text { Penca/ } \\
\text { cacho }\end{array}$ & $\begin{array}{c}\text { Massa } \\
2^{\mathrm{a}} \text { penca } \\
(\mathrm{kg})\end{array}$ & $\begin{array}{c}\text { Frutos } 2^{\mathrm{a}} \\
\text { penca }\end{array}$ & $\begin{array}{l}\text { Compr. } \\
\text { fruto }(\mathrm{cm})\end{array}$ & $\begin{array}{c}\text { Diâmetro } \\
\text { fruto }(\mathrm{mm})\end{array}$ \\
\hline \multirow{7}{*}{2003} & T1: 0 kg composto/planta & 17,70 & 126,2 & 9,4 & 2,00 & 15,4 & 13,36 & 36,70 \\
\hline & T2: 43 kg composto/planta & 16,18 & 122,2 & 9,0 & 2,05 & 15,8 & 13,08 & 36,64 \\
\hline & T3: 86 kg composto/planta & 16,20 & 123,0 & 9,0 & 1,98 & 15,6 & 13,12 & 36,46 \\
\hline & T4: $129 \mathrm{~kg}$ composto/planta & 15,29 & 120,6 & 9,2 & 1,92 & 15,8 & 12,82 & 35,96 \\
\hline & T5: $172 \mathrm{~kg}$ composto/planta & 16,44 & 123,4 & 9,0 & 2,00 & 16,4 & 12,76 & 35,72 \\
\hline & Médias & $16,36 \mathrm{AB}$ & $123,0 \mathrm{CD}$ & $9,1 \mathrm{~B}$ & $1,99 \mathrm{~A}$ & $15,8 \mathrm{AB}$ & $13,02 \mathrm{AB}$ & $36,29 \mathrm{~A}$ \\
\hline & F para doses & $0,31^{\mathrm{ns}}$ & $0,03^{\text {ns }}$ & $0,14^{\mathrm{ns}}$ & $0,12^{\mathrm{ns}}$ & $0,33^{\mathrm{ns}}$ & $0,09^{\mathrm{ns}}$ & $0,16^{\mathrm{ns}}$ \\
\hline Ano & Tratamentos & & & & & & & \\
\hline \multirow{7}{*}{2004} & T1: 0 kg composto/planta & 19,95 & 163,2 & 11,0 & 2,04 & 17,2 & 13,36 & 34,58 \\
\hline & T2: 43 kg composto/planta & 18,07 & 161,8 & 11,0 & 1,80 & 16,8 & 12,57 & 33,71 \\
\hline & T3: 86 kg composto/planta & 15,11 & 158,2 & 10,4 & 1,53 & 16,6 & 12,23 & 31,10 \\
\hline & T4: $129 \mathrm{~kg}$ composto/planta & 16,00 & 159,0 & 11,0 & 1,73 & 17,0 & 12,25 & 31,13 \\
\hline & T5: $172 \mathrm{~kg}$ composto/planta & 16,13 & 146,6 & 10,8 & 1,59 & 17,6 & 11,99 & 32,41 \\
\hline & Médias & $17,05 \mathrm{~A}$ & $157,7 \mathrm{AB}$ & $10,8 \mathrm{~A}$ & $1,74 \mathrm{~A}$ & $17,0 \mathrm{~A}$ & $12,48 \mathrm{AB}$ & $32,59 \mathrm{BC}$ \\
\hline & F para doses & $1,59^{\mathrm{ns}}$ & $0,30^{\mathrm{ns}}$ & $0,30^{\text {ns }}$ & $2,21^{\mathrm{ns}}$ & $0,35^{\text {ns }}$ & $0,42^{\mathrm{ns}}$ & $1,99 *$ \\
\hline Ano & Tratamentos & & & & & & & \\
\hline \multirow{7}{*}{2005} & T1: 0 kg composto/planta & 14,19 & 162,8 & 10,8 & 1,29 & 16,2 & 11,78 & 30,40 \\
\hline & T2: $43 \mathrm{~kg}$ composto/planta & 12,81 & 149,0 & 10,6 & 1,12 & 15,4 & 11,71 & 30,27 \\
\hline & T3: 86 kg composto/planta & 13,46 & 168,2 & 11,0 & 1,21 & 15,8 & 11,65 & 30,67 \\
\hline & T4: $129 \mathrm{~kg}$ composto/planta & 14,95 & 157,4 & 10,8 & 1,31 & 16,8 & 11,99 & 32,10 \\
\hline & T5: $172 \mathrm{~kg}$ composto/planta & 14,80 & 160,8 & 11,0 & 1,36 & 16,4 & 11,72 & 31,49 \\
\hline & Médias & $14,04 \mathrm{BC}$ & $159,6 \mathrm{~A}$ & $10,8 \mathrm{~A}$ & $1,26 \mathrm{~B}$ & $16,1 \mathrm{~A}$ & $11,77 \mathrm{~B}$ & $30,99 \mathrm{C}$ \\
\hline & F para doses & $0,34^{\mathrm{ns}}$ & $0,35^{\mathrm{ns}}$ & $0,13^{\text {ns }}$ & $0,50^{\mathrm{ns}}$ & $0,70^{\mathrm{ns}}$ & $0,03^{\text {ns }}$ & $0,51^{\text {ns }}$ \\
\hline Ano & Tratamentos & & & & & & & \\
\hline \multirow{7}{*}{2006} & T1: 0 kg composto/planta & 14,00 & 150,0 & 10,8 & 1,37 & 15,8 & 12,70 & 33,13 \\
\hline & T2: 43 kg composto/planta & 10,92 & 124,6 & 9,2 & 1,08 & 14,0 & 13,14 & 32,81 \\
\hline & T3: 86 kg composto/planta & 11,25 & 114,2 & 9,4 & 1,13 & 12,6 & 12,74 & 34,67 \\
\hline & T4: $129 \mathrm{~kg}$ composto/planta & 13,66 & 138,8 & 10,0 & 1,37 & 15,4 & 16,59 & 33,83 \\
\hline & T5: $172 \mathrm{~kg}$ composto/planta & 15,30 & 153,6 & 10,8 & 1,39 & 16,0 & 13,47 & 35,01 \\
\hline & Médias & $13,03 \mathrm{C}$ & $136,2 \mathrm{BC}$ & $10,0 \mathrm{~A}$ & $1,27 \mathrm{~B}$ & $14,7 \mathrm{BC}$ & $13,73 \mathrm{~A}$ & $33,89 \mathrm{~B}$ \\
\hline & F para doses & $1,48^{\mathrm{ns}}$ & $1,93^{\text {ns }}$ & $2,54^{\mathrm{ns}}$ & $1,21^{\mathrm{ns}}$ & $4,94 *$ & $3,92 *$ & $0,75^{\text {ns }}$ \\
\hline Ano & Tratamentos & & & & & & & \\
\hline \multirow{8}{*}{2007} & T1: 0 kg composto/planta & 9,05 & 92,2 & 8,2 & 0,95 & 13,0 & 12,96 & 34,12 \\
\hline & T2: 43 kg composto/planta & 11,45 & 109,6 & 9,0 & 1,14 & 13,8 & 13,43 & 34,45 \\
\hline & T3: 86 kg composto/planta & 10,96 & 103,6 & 8,8 & 1,03 & 13,0 & 13,41 & 34,97 \\
\hline & T4: $129 \mathrm{~kg}$ composto/planta & 13,27 & 115,8 & 9,2 & 1,34 & 14,4 & 14,42 & 35,77 \\
\hline & T5: $172 \mathrm{~kg}$ composto/planta & 13,96 & 139,8 & 10,2 & 1,14 & 15,4 & 14,41 & 33,43 \\
\hline & Médias & $11,74 \mathrm{C}$ & $112,2 \mathrm{D}$ & $9,0 \mathrm{~B}$ & $1,12 \mathrm{~B}$ & $13,9 \mathrm{C}$ & $13,73 \mathrm{~A}$ & $34,55 \mathrm{AB}$ \\
\hline & F para doses & $1,59 *$ & $2,16^{\mathrm{ns}}$ & $2,38^{\mathrm{ns}}$ & $1,20^{\mathrm{ns}}$ & $2,47^{\mathrm{ns}}$ & $0,64^{\mathrm{ns}}$ & $0,65^{\mathrm{ns}}$ \\
\hline & $\mathrm{CV}(\%)$ & 23,91 & 19,54 & 10,59 & 20,44 & 9,32 & 14,20 & 7,29 \\
\hline
\end{tabular}

Médias seguidas por letras maiúsculas distintas na coluna diferem, pelo teste de Tukey, a $5 \%$ para os anos. 


\section{CONCLUSÕES}

1. A aplicação de composto orgânico não causou alterações nas características de crescimento das plantas de bananeira-'Prata-anã' .

2. No $5^{\circ}$ ciclo de produção, os cachos com massa mais elevada foram obtidos com as duas maiores quantidades de composto aplicadas, o que indica a aplicação de $129 \mathrm{~kg}$ de composto por planta, o que corresponde a aplicação de $468,8 \mathrm{~kg}$ de $\mathrm{K}_{2} \mathrm{O}$. $\mathrm{ha}^{-1} \cdot \mathrm{ano}^{-1}$.

3. A bananeira é uma cultura que demora mais de um ciclo para responder à adubação potássica, no caso 5 ciclos.

\section{REFERÊNCIAS}

AGRIANUAL 2001: anuário estatístico da agricultura brasileira. São Paulo: FNP Consultoria \& Comércio, 2001. 492p.

BRASIL, E.C.; OEIRAS, A.H.L.; MENEZES, A.J.E.A. de; VELOSO, C.A.C. Desenvolvimento e produção de frutos de bananeira em resposta à adubação nitrogenada e potássica. Pesquisa Agropecuária Brasileira, Brasília, v.35, n.12, p.2407-2414, 2000.

CORDEIRO, Z. J. M. Sistema de produção de banana para o Estado do Pará. Disponível em: $<\mathrm{http} / / /$ sistemasdeproducao.cnptia.embrapa.br/FontesHTML/Banana/BananaPara/importancia.htm>. Acesso: 15 jan. 2007.

FAO. Food and Agriculture Organization. Disponível em: $<$ http://faostat.fao.org/faostat $>$. Acesso em: 30 jun. 2011.

GUERRA, A.G. Fertirrigação com nitrogênio e potássio utilizando sistema de irrigação por microaspersão na cultura da bananeira-'Prata-anã'. 2001. 69f. Tese (Doutorado em Agronomia/ Produção Vegetal) - Faculdade de Ciências Agrária e Veterinárias, Universidade Estadual Paulista, Jaboticabal, 2001.

GUERRA, M.P.; PEDROTTI, E.L.; REIS, M.S.; FERRARI, D.L. Resposta da bananeira 'Branca' (Grupo $\mathrm{AAB}$ ) a diferentes níveis de nitrogênio e potássio. In: CONGRESSO BRASILEIRO DE FRUTICULURA, 8., 1986, Brasília. Anais... Brasília: EMBRAPA-DDT, 1986. p.59-64.
GOMES, E.M. Crescimento e produção de bananeiras-'Prata-anã' e 'Maçã' fertirrigadas com potássio. 2004. 76f. Tese (Doutorado em Agronomia/Irrigação e Drenagem) - Faculdade de Ciências Agronômicas, Universidade Estadual Paulista, Botucatu, 2003.

KIEHL, E.J. Fertilizantes orgânicos. Piracicaba: Agronômica Ceres, 1985. 492p.

MOREIRA, R.S. Banana: teoria e prática de cultivo. Campinas: Fundação Cargill, 1987. 335p.

PEREIRA, L.V.; SILVA, C.R. de R.; ALVARENGA, A.A. Influência do tipo de muda no comportamento vegetativo e produtivo de bananeira cv. Prata-anã. Revista Brasileira de Fruticultura, Jaboticabal, v.23, n.1, p.164-167, 2001.

RAMOS, D.P.; LEONEL, S.; MISCHAN, M.M.; DAMATTO JUNIOR, E.R. Avaliação de genótipos de bananeira em Botucatu-SP. Revista Brasileira de Fruticultura, Jaboticabal, v.31, n.4, p.10921101, 2009.

RODRIGUES, M.G.V.; SOUTO, R.F.; MENEGUCCI, J.L.P. Influência do ensacamento do cacho na produção de frutos da bananeira 'Prata-anã' irrigada, na região norte de Minas Gerais. Revista Brasileira de Fruticultura, Jaboticabal, v.23, n.3, p.559-562, 2001.

RODRIGUES, M.G.V.; SOUTO, R.F.; MENEGUCCI, J.L.P. Efeito da poda da última penca do cacho na bananeira 'Prata-anã' irrigada, na produção de frutos no norte de Minas Gerais. Revista Brasileira de Fruticultura, Jaboticabal, v.24, n.1, p.108-110, 2002.

SANTOS, S.C.; CARNEIRO, L.C.; SILVEIRA NETO, A.M. da; PANIAGO JÚNIOR, E.; PEIXOTO, C.N. Caracterização morfológica e avaliação de cultivares de bananeira resistentes à Sigatoka-negra (Mycosphaerella fijiensis Morelet) no sudoeste goiano. Revista Brasileira de Fruticultura, Jaboticabal, v. 28, n. 3, p. 449-453, 2006.

SILVA, S. de O.; ALVES, E. J. Melhoramento genético e novas cultivares de bananeira. Informe Agropecuário, Belo Horizonte, v. 20, n. 196, p. 91-96, 1999. 
SILVA, J.T.A. da; BORGES, A.L.; CARVALHO, J.G.; DAMASCENO, J.E.A. Adubação com potássio e nitrogênio em três ciclos de produção da bananeira cv. Prata-anã. Revista Brasileira de Fruticultura, Jaboticabal, v.25, n.1, p.152-155, 2003.
SOTO BALLESTERO, M. Bananas: cultivo y comercialización. 2. ed. San José: Litografia e Imprensa, 1992. $674 \mathrm{p}$. 